\title{
Chronic neck and shoulder pain, age, and working conditions: longitudinal results from a large random sample in France
}

\author{
B Cassou, F Derriennic, C Monfort, J Norton, A Touranchet
}

Occup Environ Med 2002;59:537-544

See end of article for authors' affiliations

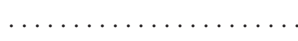

Correspondence to: Dr B Cassou, Laboratoire santé-vieillissement, 49 rue Mirabeau, 75016, Paris, France; bernard.cassou@ spr.ap-hop-paris.fr

Accepted 12 March 2002

\begin{abstract}
Aims: To analyse the effects of age and occupational factors on both the incidence and the disappearance of chronic neck and shoulder pain after a five year follow up period.

Methods: A prospective longitudinal investigation (ESTEV) was carried out in 1990 and 1995 in seven regions of France. A random sample of male and female workers born in 1938, 1943, 1948, and 1953 was selected from the occupational physicians' files. In 1990, 21378 subjects were interviewed $(88 \%$ of those contacted), and $87 \%$ were interviewed again in 1995 . Chronic neck and shoulder pain satisfying specific criteria, and psychosocial working conditions were investigated by a structured self administered questionnaire and a clinical examination.

Results: Prevalence (men $7.8 \%$, women $14.8 \%$ in 1990) and incidence (men $7.3 \%$, women $12.5 \%$ for the period 1990-95) of chronic neck and shoulder pain increased with age, and were more frequent among women than men in every birth cohort. The disappearance rate of chronic neck and shoulder pain decreased with age. Some adverse working conditions (repetitive work under time constraints, awkward work for men, repetitive work for women) contributed to the development of these disorders, independently of age. Psychosocial factors seemed to play a role in both the development and disappearance of chronic neck and shoulder pain. Data did not show specific interactions between age and working conditions.

Conclusions: The aging of the workforce appears to contribute to the widespread concern about chronic neck and shoulder pain. A better understanding of work activity regulation of older workers can open up new preventive prospects.
\end{abstract}

P in in the upper limbs is a major work related health problem in many countries. ${ }^{1}$ In France, according to official statistics of compensation claims, the number of subjects with occupational diseases in the upper limbs was six times higher in $1994(n=3963)$ than in $1985(n=673)$. These disorders accounted for $50 \%$ of all reported occupational diseases. ${ }^{2}$ Among such disorders, pain in the neck and shoulders often causes disability and time lost from work.

It has been shown in two recent reviews, ${ }^{34}$ that there is evidence of a relation between musculoskeletal disorders in the neck and shoulder and physical and psychosocial factors at work. These factors include biomechanical factors, such as posture and static loading of muscles, vibrations, and frequency, duration, and force of repetitive movements. ${ }^{5-8}$ Administrative and organisational factors, such as job control and psychological job demand, are also important factors. ${ }^{9}{ }^{10}$

However, most of these surveys were limited to cross sectional data, offering weak evidence for causality as a result of uncertainty over the time of exposure and bias by a health related selection of employees. ${ }^{1}$ Some studies focused on only one or a few risk factors. Many of these studies concerned jobs (construction, dentistry, forestry, nursing, office jobs) without measures of psychosocial factors. ${ }^{112}$ A number of studies used an outcome measure which was a mixture of acute and chronic disorders.

Moreover, no clear conclusion about the role of aging in relation to neck and shoulder pain could be drawn from these studies, as the effect of age was not one of their primary objectives. They included participants of a wide age range. In the past year, several cross sectional studies on musculoskeletal complaints have reported a sharp increase in prevalence rates with advancing age for both male and female workers. However, the effects linked to a particular generation and those specific to age itself are not clearly distinguished. Age is only considered as a confounder.

At this point in time, many questions remain unanswered concerning the role of psychosocial, objective measurable work factors and aging on the development of neck and shoulder pain. ${ }^{13}$ With increasing age, degenerative changes do occur in joints and tissues which result in neck and shoulder pain. Therefore, it seems reasonable that the aging of the workforce can contribute to the increased awareness and incidence of musculoskeletal disorders.

We therefore used the data from the French longitudinal ESTEV (Health Work and Aging Investigation) Study, carried out in a large representative sample of workers from various occupations, to study the effects of aging and investigate some work related factors as predictors of chronic neck and shoulder pain. We wanted to clarify the combined effects of age, physical, and psychosocial work demands on neck and shoulder pain in terms of both incidence and disappearance, after a prospective five year follow up.

\section{SUBJECTS AND METHODS}

The aim of ESTEV, a prospective longitudinal epidemiological investigation on which this study was based, was to identify occupational factors that might modify the evolution over time of some health characteristics, and to specify the effect of aging. ${ }^{14}$

\section{Population}

The sample population in 1990 was randomly selected from exhaustive lists of workers under the supervision of $400 \mathrm{occu}-$ pational physicians. The occupational physicians participated on a voluntary basis after receiving some information about 
the survey and follow up through the Regional Occupational Physician Society. They came from seven regions of France, offering a good contrast from a socioeconomic point of view: Bretagne, Dauphiné, Ile de France, Nord, Pays de Loire, Val de Loire, and Ile de la Réunion.

The survey took place during the annual occupational medical examination in 1990 and 1995. For each physician, the sample selection was stratified by sex and the four years of birth considered (1938, 1943, 1948, and 1953), by varying the sampling rate per stratum according to the distribution of each stratum among all French employees. These sampling rates were deduced from the national employment statistics.

Participants completed two questionnaires with closed questions, and a medical examination was carried out by the occupational physician.

\section{Pain status}

Neck and shoulder pain status was based on the presence of pain reported by the worker combined with a clinical examination to check the location of pains. Clinical examination was performed by a trained occupational physician during working hours. Questions were also asked about symptoms in other body locations. No illustration was used to define the anatomical area of the neck and shoulder. The physician completed the medical questionnaire. Among subjects reporting pain, we collected further information on health seeking behaviour. The subjects were asked if they had consulted and been treated by a physician, whether the pain was associated with functional limitation, and if they had stopped working (on sick leave) in relation to the pain. Cases with chronic pain were identified as those persons who declared, on the day of the medical examination, pain lasting at least six months (duration of current episode or intermittent complaints over the last six months) with functional limitations. Each subject received a physical examination of the neck and shoulder, consisting of passive motion. The worker was asked to indicate discomfort from any motion. This definition, incorporating both duration and functional limitation, was chosen to exclude those with either transient or relatively mild neck and shoulder pain. Hereafter, the term chronic neck and shoulder pain (CNSP) will be used to define subjects meeting the above criteria.

\section{Working conditions}

Exposures were assessed using a checklist of work conditions filled in by the workers and controlled by the physician. The questionnaire included 30 questions on different kinds of physical activities at work and the psychosocial work environment. The questions were derived from ergonomic and epidemiological studies previously carried out in France. ${ }^{15}$ A feasibility study was performed on about 200 workers to check the intelligibility of the questions. There were three possible answers for each question: exposed at work at the time of the interview (1990); not exposed in 1990 but exposed in the past; and never exposed. For the exposures in 1990, the occupational physician checked the coherence between the worker's declarations and the information about the worker's workplace in the medical file.

A subject was considered to be exposed to awkward work if he stated that he was exposed to at least one of the following constraints: awkward posture, carrying heavy loads, vibrations, or work exertion required to operate tools or machines. A subject was considered to have low job control if he stated that he was exposed to at least one of the following factors: no means available to carry out high quality work (material, information, time), no possibility of choosing oneself the way in which the work will be carried out, no diversification of work, or no learning of new things at work. A subject was considered to have high job demand if he stated that he was exposed to at least one of the following factors: to have to hurry, to have to do several things at the same time, or to be interrupted often while working. Repetitive work under time constraints, shift work (alternating shifts, getting up early, night work) and precise movements were assessed with one question for each exposure.

The intensity and frequency of exposure were not recorded. Subjects were, however, classified into three groups according to the duration of exposure to repetitive work, awkward work, and shift work: never, less than 10 years, and 10 years or more.

Social class was determined by placing the job into one of the four categories of the INSEE (Institut National de la Statistique et des Etudes Economiques) classification: white collar workers (senior and junior executives and technical workers), clerks (clerical and sales personnel), blue collar workers (foremen, skilled and unskilled workers, and service workers), and other occupations.

\section{Confounders}

Finally, to assess potential confounding factors, the physician completed a medical questionnaire by using a standard protocol that listed past and current disorders, age at first appearance of each disease and any treatment prescribed, and clinical and anthropometric data. The medical history also included questions on previous injuries and diseases of the musculoskeletal system, classified according to the ninth International Classification of Diseases. Only the diseases that occurred before 1990 (thus excluding the current diseases at the time of the survey) were recorded. The occupational physician used the subject's medical file. Symptoms of depression, at the time of the survey, were assessed by means of two items from the Nottingham Health Profile. The physician also asked the subject about smoking habits (non-smoker, smoker before 1990, current smoker), and sporting activities at the time of the survey.

\section{Statistical analysis}

Data were collected again in 1995 with the same questions and clinical examination as in 1990. The change in symptom status from 1990 to 1995 was investigated, and data from the 1990 questionnaire were used to define potential predictors.

The same statistical analysis was planned to examine the role of various factors for the incidence of neck and shoulder pain (only among subjects who stated they had no CNSP in 1990), and for the disappearance of neck and shoulder pain (only among subjects who stated they had CNSP in 1990) after the five year follow up. The analysis only concerned the subjects seen twice and still at work in 1995, in order to avoid any bias related to exclusion from work. The bivariate analyses concerned the association, adjusted on the year of birth cohorts selected $(1938,1943,1948,1953)$, according to sex, between the frequency of neck and shoulder chronic pain and each of the subgroups of variables described above. These associations were tested with the Mantel-Haenszel $\chi^{2}$ test, with $5 \%$ as level of significance.

The generational effect on prevalence was evaluated as the difference of the prevalence at the same age in two different birth cohorts. Considering the framework of the sampling procedure, only differences at ages 42,47 , and 52 were considered. The effect of aging was evaluated by examination of the evolution of the prevalence in each birth cohort. Each of these effects (generational and aging effects) could not exclude some contributing differences between the dates of observation - that is, 1990 and 1995

Multivariate analysis was performed for both components of the study, the incidence and disappearance of chronic neck and shoulder pain, using the same analytical strategy for each component. The presence or absence of chronic neck and shoulder pain was the dependent variable. The explanatory variables were coded in such a way that the reference response was that presumed to prevent neck and shoulder pain: age 
Table 1 Baseline characteristics of the subjects

\begin{tabular}{|c|c|c|c|c|c|c|c|c|}
\hline & \multicolumn{4}{|l|}{$\begin{array}{l}\text { Men } \\
\text { Birth year }\end{array}$} & \multicolumn{4}{|l|}{$\begin{array}{l}\text { Women } \\
\text { Birth year }\end{array}$} \\
\hline & $\begin{array}{l}1953 \\
n=2640 \\
\%\end{array}$ & $\begin{array}{l}1948 \\
n=2769 \\
\%\end{array}$ & $\begin{array}{l}1943 \\
n=2667 \\
\%\end{array}$ & $\begin{array}{l}1938 \\
n=1711 \\
\%\end{array}$ & $\begin{array}{l}1953 \\
n=1922 \\
\%\end{array}$ & $\begin{array}{l}1948 \\
n=1893 \\
\%\end{array}$ & $\begin{array}{l}1943 \\
n=1978 \\
\%\end{array}$ & $\begin{array}{l}1938 \\
n=1370 \\
\%\end{array}$ \\
\hline \multicolumn{9}{|l|}{ Social class } \\
\hline Executives & 28.6 & 32.6 & 36.4 & 31.0 & 21.9 & 21.5 & 21.0 & 16.4 \\
\hline Clerks & 9.3 & 8.1 & 7.6 & 8.3 & 51.8 & 52.5 & 50.6 & 55.3 \\
\hline Blue collar workers & 59.8 & 56.1 & 53.1 & 57.3 & 24.9 & 24.5 & 26.3 & 26.2 \\
\hline Others & 2.3 & 3.2 & 2.9 & 3.4 & 1.4 & 1.5 & 2.1 & 2.1 \\
\hline \multicolumn{9}{|c|}{ Working conditions in 1990} \\
\hline Repetitive work & 10.0 & 8.5 & 8.4 & 8.8 & 11.9 & 10.0 & 11.2 & 9.6 \\
\hline Awkward work & 64.8 & 61.2 & 60.3 & 61.9 & 40.6 & 42.4 & 45.4 & 48.9 \\
\hline Precise movements & 29.0 & 28.6 & 25.8 & 24.6 & 21.4 & 20.5 & 20.1 & 19.2 \\
\hline High job demand & 55.4 & 56.8 & 56.5 & 52.6 & 59.2 & 56.6 & 57.7 & 54.5 \\
\hline Low job control & 17.4 & 14.7 & 18.1 & 21.0 & 23.9 & 23.1 & 24.8 & 29.0 \\
\hline Shift work & 30.3 & 29.0 & 27.9 & 25.8 & 15.5 & 16.3 & 16.2 & 15.0 \\
\hline
\end{tabular}

( $r e f=37$ years), social class $(r e f=$ executives $)$, repetitive work $($ ref $=$ never $)$, awkward work (ref = never), precise movement $(\mathrm{ref}=\mathrm{no})$, job demand $(\mathrm{ref}=\mathrm{low})$, job control (ref $=$ high), shift work (ref = never), depressive symptoms $(\mathrm{ref}=\mathrm{no})$, musculoskeletal diseases in the past (ref $=$ no), sporting activities $(\mathrm{ref}=\mathrm{no})$, and smoking ( $\mathrm{ref}=\mathrm{no})$. The logistic regression used an ascending stepwise procedure. The significance level at which variables were entered and removed from the model was set at $10 \%$. The factors that were significantly associated with chronic neck and shoulder pain in the bivariate analysis were only included in the ascending stepwise procedure. Only the final model configuration with the best fit is presented. The same procedure was also carried out in order to test possible interactions between age and occupational factors; product terms "age.occupational factors" were entered in the final model. Calculations were carried out on a UNIX server from the Centre de Ressources Informatiques of INSERM, using BMDP and SAS software.

\section{RESULTS}

In 1990, 24228 subjects, men and women, who were born in 1953, 1948, 1943, or 1938, were randomly selected. Only 21378 subjects participated at the first stage in 1990. The rate of participation was $88.2 \%$ and did not vary by more than $1 \%$ by age, sex, or region. Of the 21378 respondents in 1990 (57\% were men), 18695 were interviewed again in 1995-a follow up rate of $87.4 \%$. The distribution by age remained balanced for the first three cohorts, in both sexes. However, the proportion of subjects born in 1938 and followed up in 1995 was lower in both sexes. The number of subjsects lost to follow up was thus proportionally higher for the oldest generation. For that generation also, more subjects were no longer working in 1995. In the population as a whole, 16950 subjects were still at work in 1995 (90.6\% of the follow up sample).

The distribution of social class was not the same in both sexes (table 1). There were more executives and blue collar workers among men and more clerks among women. The working conditions were found to be related to gender and birth cohort. Men declared awkward work and shift work more often than women. Women, more often than men, declared repetitive work under time constraints and low job control. Some differences were also found according to generation. The frequency of depressive symptoms, musculoskeletal diseases in the past, sporting activities in 1990, and smoking status differed according to sex and generation.

For men, the prevalence rate was $7.8 \%$ in 1990 and $9.5 \%$ in 1995. For women, these rates were $14.8 \%$ and $17.6 \%$. In 1990, as in 1995, the prevalence of CNSP increased with age among men and women (fig 1). In each birth cohort, at both dates, the

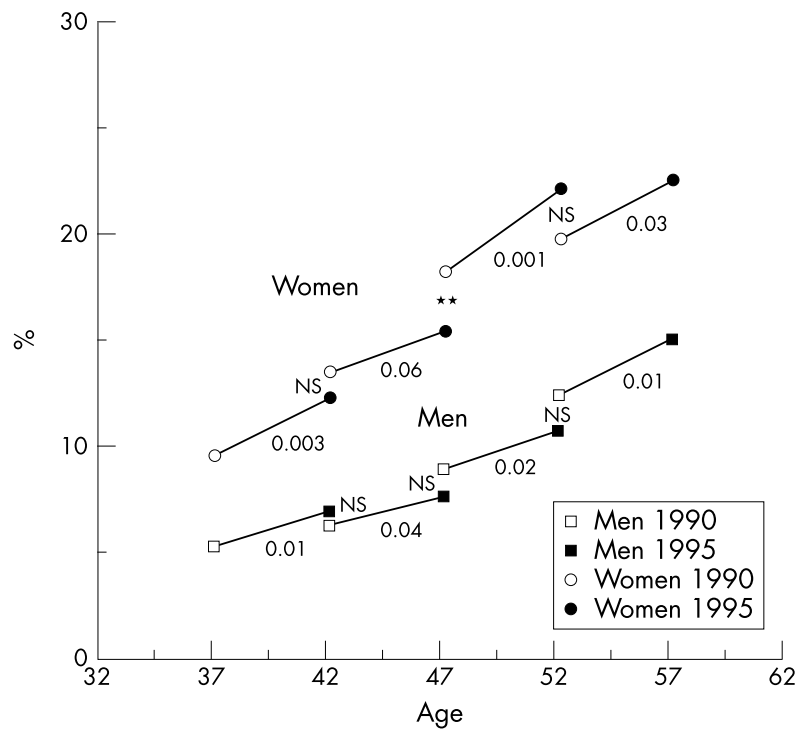

Figure 1 Evolution between 1990 and 1995 of the prevalence rate of chronic neck and shoulder pain according to sex.

prevalence was higher among women than men $(\mathrm{p}<0.001)$. Moreover, for each age, the prevalence rate was different according to the generation: lower among the younger generation for men aged 47 and 52 years, and for women aged 42 and 47 years. Although there appeared to be an effect of generation (fig l), the only comparison that reached statistical significance was that for 47 year old women $(\mathrm{p}<0.01)$.

On the whole, $85.5 \%$ of men and $74.5 \%$ of women were free of CNSP in 1990 and 1995, while $2.7 \%$ of men and $7.0 \%$ of women declared pains in 1990 and 1995. The incidence of CNSP (among subjects not suffering from neck and shoulder pain in 1990) increased with age among men and women (table 2). For each birth cohort, incidence rate was lower among men than among women $(\mathrm{p}<0.001)$. Among subjects with CNSP in $1990,64.8 \%$ of men and $53.2 \%$ of women did not declare pain in this localisation in $1995(\mathrm{p}<0.001)$. The disappearance rate decreased with age, especially among women.

The incidence of CNSP was not statistically different among men according to social class (executives 6.7\%; clerks $7.8 \%$; blue collar workers $7.5 \%$; others $8.2 \%$ ). It was also the same for the disappearance rate of symptoms (executives $61.1 \%$; clerks $73.2 \%$; blue collar workers $65.4 \%$; others $72.2 \%$ ). For women, there was no relation between social class and incidence of symptoms (executives 12.4\%; clerks 12.6\%; blue collar workers 
Table 2 Incidence and disappearance rate of chronic neck and shoulder pain according to sex

\begin{tabular}{|c|c|c|c|c|c|c|}
\hline \multirow[b]{2}{*}{ Birth year } & \multicolumn{3}{|c|}{ Incidence* (\%) } & \multicolumn{3}{|c|}{ Disappearance† (\%) } \\
\hline & $\begin{array}{l}\text { Men } \\
n=9028\end{array}$ & $\begin{array}{l}\text { Women } \\
n=6100\end{array}$ & $p$ value & $\begin{array}{l}\text { Men } \\
n=759\end{array}$ & $\begin{array}{l}\text { Women } \\
n=1063\end{array}$ & $\mathrm{p}$ value \\
\hline 1953 & 5.2 & 9.5 & 0.001 & 63.8 & 63.2 & NS \\
\hline 1948 & 6.2 & 11.2 & 0.001 & 72.7 & 58.5 & 0.01 \\
\hline 1943 & 8.3 & 15.3 & 0.001 & 65.1 & 47.9 & 0.001 \\
\hline 1938 & 11.1 & 15.2 & 0.001 & 58.8 & 48.3 & 0.05 \\
\hline All samples & 7.3 & 12.5 & 0.001 & 64.8 & 53.2 & 0.001 \\
\hline
\end{tabular}

*Among subjects not suffering from chronic neck and shoulder pain in 1990.

†Among subjects who stated they had chronic neck and shoulder pain in 1990.

NS, not significant.

\begin{tabular}{|c|c|c|c|c|}
\hline \multirow[b]{3}{*}{ Occupational factors in 1990} & \multicolumn{4}{|c|}{ Incidence } \\
\hline & \multicolumn{2}{|c|}{$\begin{array}{l}\text { Men } \\
n=9028\end{array}$} & \multicolumn{2}{|c|}{$\begin{array}{l}\text { Women } \\
n=6100\end{array}$} \\
\hline & $\%$ & p value* & $\%$ & p value* \\
\hline \multicolumn{5}{|l|}{ Repetitive work } \\
\hline Never & 7.1 & & 11.9 & \\
\hline Before 1990 & 9.6 & 0.01 & 14.5 & 0.01 \\
\hline $\ln 1990$ & 6.4 & & 15.0 & \\
\hline \multicolumn{5}{|l|}{ Awkward work } \\
\hline Never & 5.6 & & 11.3 & \\
\hline Before 1990 & 7.9 & 0.01 & 12.1 & 0.04 \\
\hline $\ln 1990$ & 7.7 & & 13.9 & \\
\hline \multicolumn{5}{|l|}{ Precise movements } \\
\hline No & 7.1 & & 11.5 & \\
\hline Yes & 7.5 & NS & 14.2 & 0.001 \\
\hline \multicolumn{5}{|l|}{ Job demand } \\
\hline Low & 6.7 & $80 ?$ & 11.6 & 005 \\
\hline High & 7.8 & 0.03 & 13.2 & 0.05 \\
\hline \multicolumn{5}{|l|}{ Job control } \\
\hline Low & 7.5 & & 14.2 & \\
\hline High & 7.3 & NS & 12.0 & 0.03 \\
\hline \multicolumn{5}{|l|}{ Shift work } \\
\hline Never & 6.8 & & 11.9 & \\
\hline Before 1990 & 8.5 & NS & 13.9 & NS \\
\hline $\ln 1990$ & 7.1 & & 14.0 & \\
\hline
\end{tabular}

$12.3 \%$; others $13.7 \%, \mathrm{p}<0.06$ ), and no significant relation between social class and disappearance of CNSP (executives $58.6 \%$; clerks $49.1 \%$; blue collar workers $55.6 \%$; others $66.7 \%$ ).

For men, the relation between working conditions and the incidence of pain was statistically significant for repetitive work, awkward work, and high job demand (table 3). For women, there was a significant statistical relation with repetitive work under time constraints, awkward work, precise movements, high job demand, and low job control. The presence of these factors (in 1990 or before) was associated with an increase in the incidence of chronic pain, except for repetitive work among men.

For men and women, there was a significant statistical relation between job demand and disappearance rate; the highest rate was for the subjects who in 1990, declared low job demand (table 4). Moreover, women who were exposed to repetitive work under time constraints before 1990 had the lowest disappearance rates.

To analyse the specific effects of age and working conditions on incidence and disappearance, we used logistic regression models with an ascending stepwise procedure. We only present the final model configuration with the best fit.

In both sexes, incidence increased with age independently of working conditions (table 5). Among men, the occupational factors that appeared to be risk factors for the incidence of pain, independent of age were: repetitive work under time constraints before 1990, awkward work in 1990, and high job demand in 1990. Two occupational factors were related to the incidence among women: repetitive work under time constraints in 1990 and before, and high job demand in 1990. In both sexes, depressive symptoms in 1990 and musculoskeletal diseases in the past were also risk factors independent of age and occupational factors. Among men, the incidence of pain decreased among those with sporting activities and increased among smokers before 1990. The fit was 0.63 for the male model and 0.32 for the female model.

For women (table 6), disappearance was related to age, independent of the other factors. Disappearance rate was lowest for the two older groups. For men, the age variable did not enter the final model. For both sexes, high job demand was associated with the lowest disappearance rate. Only among women was the same relation found with repetitive work in the past. For both sexes, the disappearance rate was significantly lower among subjects with musculoskeletal diseases in the past, independent of age and working factors. Men who declared sporting activities in 1990 seemed to have a higher disappearance rate than subjects without sporting activities in 1990. There was no statistically significant relation 


\begin{tabular}{|c|c|c|c|c|}
\hline \multirow[b]{3}{*}{ Occupational factors in 1990} & \multicolumn{4}{|c|}{ Disappearance } \\
\hline & \multicolumn{2}{|c|}{$\begin{array}{l}\text { Men } \\
n=759\end{array}$} & \multicolumn{2}{|c|}{$\begin{array}{l}\text { Women } \\
n=1063\end{array}$} \\
\hline & $\%$ & $\mathrm{p}$ value* & $\%$ & p value* \\
\hline \multicolumn{5}{|l|}{ Repetitive work } \\
\hline Never & 65.2 & \multirow{3}{*}{ NS } & 55.1 & \multirow{3}{*}{0.002} \\
\hline Before 1990 & 63.6 & & 38.2 & \\
\hline $\ln 1990$ & 62.9 & & 56.4 & \\
\hline \multicolumn{5}{|l|}{ Awkward work } \\
\hline Never & 72.2 & \multirow{3}{*}{ NS } & 57.4 & \multirow{3}{*}{ NS } \\
\hline Before 1990 & 67.3 & & 54.9 & \\
\hline $\ln 1990$ & 62.5 & & 49.5 & \\
\hline \multicolumn{5}{|l|}{ Precise movements } \\
\hline No & 66.6 & \multirow{2}{*}{ NS } & 52.1 & \multirow{2}{*}{ NS } \\
\hline Yes & 63.1 & & 54.8 & \\
\hline \multicolumn{5}{|l|}{ Job demand } \\
\hline Low & 69.8 & \multirow{2}{*}{0.02} & 57.2 & \multirow{2}{*}{0.02} \\
\hline High & 61.2 & & 50.4 & \\
\hline \multicolumn{5}{|l|}{ Job control } \\
\hline Low & 67.7 & \multirow{2}{*}{ NS } & 50.9 & \multirow{2}{*}{ NS } \\
\hline High & 64.2 & & 54.1 & \\
\hline \multicolumn{5}{|l|}{ Shift work } \\
\hline Never & 66.8 & \multirow{3}{*}{ NS } & 54.9 & \multirow{3}{*}{ NS } \\
\hline Before 1990 & 64.8 & & 48.9 & \\
\hline $\ln 1990$ & 61.7 & & 50.5 & \\
\hline
\end{tabular}

*Adjustment for birthday with the Mantel-Haenszel $\chi^{2}$ test. NS, not significant.

Table 5 Incidence of chronic neck and shoulder pain according to sex; logistic regression with ascending stepwise procedure

\begin{tabular}{|c|c|c|c|c|}
\hline \multirow[b]{3}{*}{ Factors in 1990} & \multicolumn{4}{|c|}{ Incidence } \\
\hline & \multicolumn{2}{|c|}{$\begin{array}{l}\text { Men } \\
n=8952\end{array}$} & \multicolumn{2}{|c|}{$\begin{array}{l}\text { Women } \\
n=6043\end{array}$} \\
\hline & OR & $95 \% \mathrm{Cl}$ & OR & $95 \% \mathrm{Cl}$ \\
\hline \multicolumn{5}{|c|}{ Year of birth (ref=1953) } \\
\hline 1948 & 1.1 & (0.9 to 1.4 ) & 1.2 & (1.0 to 1.5$)$ \\
\hline 1945 & 1.5 & (1.2 to 1.9$)$ & 1.6 & $(1.3$ to 2.0$)$ \\
\hline 1938 & 2.0 & (1.6 to 2.6$)$ & 1.5 & (1.2 to 2.0$)$ \\
\hline \multicolumn{5}{|c|}{ Repetitive work (ref=never) } \\
\hline $\ln 1990$ & 0.9 & $(0.7$ to 1.2$)$ & 1.3 & $(1.0$ to 1.6$)$ \\
\hline Before 1990 & 1.3 & (1.0 to 1.7$)$ & 1.2 & $(1.0$ to 1.5$)$ \\
\hline \multicolumn{5}{|c|}{ Awkward work (ref=never) } \\
\hline $\ln 1990$ & 1.3 & (1.1 to 1.7$)$ & // & // \\
\hline Before 1990 & 1.2 & (0.9 to 1.6$)$ & $/ /$ & // \\
\hline \multicolumn{5}{|c|}{ Job demand (ref=low) } \\
\hline High & 1.2 & $(1.0$ to 1.4$)$ & 1.2 & (1.0 to 1.4$)$ \\
\hline \multicolumn{5}{|c|}{ Depressive symptoms (ref=no) } \\
\hline Yes & 1.3 & (1.0 to 1.8$)$ & 1.5 & (1.2 to 1.9 ) \\
\hline \multicolumn{5}{|c|}{ MSD in the past $(r e f=n o)$} \\
\hline Yes & 1.5 & (1.3 to 1.8$)$ & 1.7 & (1.5 to 2.0 ) \\
\hline \multicolumn{5}{|c|}{ Sporting activities (ref=no) } \\
\hline Yes & 0.8 & $(0.7$ to 0.9$)$ & // & // \\
\hline \multicolumn{5}{|l|}{ Smoking (ref=no) } \\
\hline $\ln 1990$ & 0.9 & (0.8 to 1.2 ) & // & // \\
\hline Before 1990 & 1.2 & (1.0 to 1.4 ) & // & /1 \\
\hline
\end{tabular}

between depressive symptoms and disappearance rate. The fit was 0.76 for the male model and 0.80 for the female model.

For the incidence of CNSP, no interaction between age and working conditions was detected. For disappearance, only one interaction was detected between age and repetitive work under time constraints. Men born in 1953 and exposed in 1990 declared a lower disappearance than men of the same birth cohort who had never been exposed or only exposed in the past.

When the subjects were studied as a whole, gender was a factor acting independently of the other factors on both inci- dence and disappearance. The incidence was higher for women than for men, and the disappearance was higher for men than for women.

\section{DISCUSSION}

Our study emphasises the multifactorial nature of chronic neck and shoulder pain in the working population. It shows links between age and CNSP among workers older than 37 
Table 6 Disappearance of chronic neck and shoulder pain according to sex; logistic regression with ascending stepwise procedure

\begin{tabular}{|c|c|c|c|c|}
\hline \multirow[b]{3}{*}{ Factors in 1990} & \multicolumn{4}{|c|}{ Disappearance } \\
\hline & \multicolumn{2}{|c|}{$\begin{array}{l}\text { Men } \\
n=748\end{array}$} & \multicolumn{2}{|c|}{$\begin{array}{l}\text { Women } \\
n=1056\end{array}$} \\
\hline & OR & $95 \% \mathrm{Cl}$ & OR & $95 \% \mathrm{Cl}$ \\
\hline \multicolumn{5}{|l|}{ Years of birth (ref=1953) } \\
\hline 1948 & 1.5 & (0.9 to 2.5$)$ & 0.8 & (0.5 to 1.2$)$ \\
\hline 1945 & 1.2 & $(0.8$ to 1.9$)$ & 0.6 & $(0.4$ to 0.8$)$ \\
\hline 1938 & 1.0 & $(0.6$ to 1.5$)$ & 0.6 & $(0.4$ to 0.9$)$ \\
\hline \multicolumn{5}{|l|}{ Repetitive work (ref=never) } \\
\hline $\ln 1990$ & $/ /$ & $/ /$ & 0.8 & (0.5 to 1.3$)$ \\
\hline Before 1990 & // & // & 0.5 & $(0.3$ to 0.7$)$ \\
\hline \multicolumn{5}{|l|}{ Job demand (ref=low) } \\
\hline High & 0.7 & $(0.5$ to 0.9$)$ & 0.7 & $(0.6$ to 0.9$)$ \\
\hline $\begin{array}{l}\text { MSD in the past (ref=no) } \\
\text { Yes }\end{array}$ & & & & \\
\hline \multicolumn{5}{|l|}{ Yes } \\
\hline Yes & 1.5 & (1.1 to 2.1 ) & $/ /$ & $/ /$ \\
\hline
\end{tabular}

OR, odds ratio; $95 \% \mathrm{Cl}$, confidence interval; ref, reference; $\mathrm{MSD}$, musculoskeletal diseases in the past; //, variable not selected in the best model.

years. Some moderate generational effects are observed. However, the relation between age and CNSP is independent of these effects.

How can the age effect be explained? Firstly, biological changes related to the aging process, for example, degenerative changes of muscles, tendons, ligaments, and joints, are suggested to contribute to the pathogenesis of musculoskeletal disorders. Secondly, the increasing number of years in service during which aging workers are exposed to harmful work demands may be associated with an increased risk of disorders. The disorders found in this study may have arisen as a consequence of many years of accumulated workload. Thirdly, a chronic overload for the elderly worker caused by a disruption of the balance between physical workload and physical work capacity with advancing age has also been suggested as a potential cause for the development of musculoskeletal disorders. ${ }^{16}$ Increasing age may increase the susceptibility of tissues to physical loads.

Our study confirms the relation between some adverse working conditions and the incidence of CNSP, independent of age. During the past decade, the knowledge of aetiological factors and occupational exposures has increased, and work related factors such as repetitive work, awkward postures, and vibration have been related to neck and shoulder disorders. ${ }^{134}$ Earlier studies of psychological factors suggested that low job control and high job demand are positively associated with musculoskeletal symptoms, in particular neck and shoulder disorders. ${ }^{9}{ }^{10}$ In our study, psychosocial factors seem to play a role in both the development and the disappearance of CNSP. There are, however, a few studies which have investigated, in the same survey, the main potential aetiological factors. In our study, we have tried to evaluate the relative contribution of these occupational risk factors, aging (in distinguishing generational effect from aging), and some potential confounding variables.

Our data also support some findings already noted in the literature about history of musculoskeletal disorders in the past, depressive symptoms, and smoking as risk factors of neck and shoulder pain. ${ }^{17-19}$ Sporting activities seem to be a protective factor. ${ }^{20}$ However, all these variables (depressive symptoms, musculoskeletal diseases in the past, sporting activities, and smoking) were only considered as confounder variables and roughly evaluated.

Most associations found between work related risk determinants and the incidence/disappearance of CNSP are quite weak. Nevertheless, three complementary statistical analyses reinforce the possible relation between some work exposures and the presence of CNSP. We have searched for evidence of a trend (by non-zero correlation Mantel-Haenszel test) when more than two categories were examined and a signifiance level noted. Among men, for the incidence, there is a significant trend with awkward work $(p<0.01)$. Subjects exposed in the past had the highest incidence, which could represent a long term effect of awkward factors after a period without symptoms. Among women, there are two significant trends with repetitive work $(\mathrm{p}<0.01)$ and awkward work $(\mathrm{p}<0.02)$. The incidence increased from the subjects never exposed to the subjects exposed in 1990. Women exposed in the past had an intermediate rate, which suggests a long term effect of past work factors.

On the other hand, we have taken into account the fact that, in the period 1990-95, some subjects had been exposed to new occupational risks and others had been removed from the potentially risky exposures. For three work factors (repetitive work, awkward work, and shift work), we have scored the subjects according the presence or absence of the exposures in 1990 and 1995 (exposed in 1990-exposed in 1995, exposednot exposed, not exposed-exposed, and not exposed-not exposed). We have introduced these variables in a logistic regression with four other variables (age, exposed to repetitive work before 1990, awkward work before 1990, and shift work before 1990) to determine if age, pre-1990 exposure, and changes in the period 1990-95 were predictors of CNSP in 1995. For the men, age, repetitive work before $1990(\mathrm{OR}=1.3$, CI 1.0 to 1.6), and awkward work before 1990 (OR = 1.3, CI 1.0 to 1.7 ) were only related to the incidence of CNSP. For the women, age and repetitive work before 1990 were only related to the incidence of CNSP. These results reinforce the possible long term effect of some occupational exposures. Occupational exposure changes in the period 1990-95 seem not to be a predictor of CNSP in 1995.

Finally, there is a relation between the duration of awkward work exposure (never, less than 10 years, 10 years and more) and the incidence of CNSP among men $(p<0.008)$ and women (not significant), subjects with the longest duration having the highest incidence. There is also a relation (not statistically significant) between the duration of repetitive work exposure, awkward work exposure, and shift work exposure and the disappearance of CNSP, subjects with the longest duration having the lowest disappearance rate.

No age-work variable interactions were significant for the incidence. Data show only one interaction between age and working conditions for the disappearance: men born in 1953 and exposed in 1990 had declared a lower disappearance than 
men of the same birth cohort and never exposed or only exposed in the past. It could be a random effect, but could be mean that the stress related to repetitive work under time constraints was higher among the youngest men than the others, and so the disappearance rate was lower among the youngest men.

The ESTEV sample population included workers, in the second half of their careers, followed by an occupational physician, and working mainly in private industry and trade. Although the geographic regions surveyed covered the diversity of the socioeconomic situation in France, we cannot guarantee that the sample population is representative of the entire French working population. In selecting the sampling rate based on the National Statistics and applying it locally to the seven regions, we checked that the regional distributions of workers according to age, sex, social class, and economic sector (private or public) did not differ remarkably from the National Statistics. The fluctuations were very small, except for "La Réunion" area for social class and economic sectors. However, it represented only $5 \%$ of the sample. It is, however, a random sample selected from an exhaustive list of employees who were patients of the occupational physicians participating in the survey. In France, about 75\% of the workforce is under the supervision of occupational physicians. The high rate of participation ( $88 \%$ in 1990, and $87 \%$ in 1995), stable for age and sex in all seven regions, limited the potential bias coming from non-participation. In 1990, among the subjects selected but not interviewed, the reasons for non-participation were: to refuse to participate, $50 \%$ (irrespective of age and sex); out of work (moving, unemployment), 16.6\%; impossibility to go to the occupational clinical examination, $8.3 \%$; sick leave, $8.3 \%$; and unknown reasons, $16.8 \%$.

Validity and reliability of exposure should be discussed. The choice of an assessment technique for exposure to work factors in musculoskeletal epidemiology depends on its feasibility in a large sample. Information is commonly gathered from the worker's response to questions in self administered questionnaires. Self reports yield information that is subject to systematic bias and lack of precision. The possibility of response bias resulting from subjects' appreciation of a possible gain or decrement in their employment from the use of their answers is unlikely. All questionnaires used in the survey were anonymous, and this fact had been clearly specified to each potential participant who could refuse to be enrolled in the sample. The frequency of missing data was very low, $2 \%$ on average. The validity of the information on working conditions in the questionnaire of this study was controlled by the occupational physician for the exposures in 1990. The occupational physician checked the coherence of the workers' statements with the information on the job specification sheet included in the medical file. In case of disagreement, the worker's opinion prevailed. About $2 \%$ of the workers' statements were corrected. Nevertheless, the recall of work load in the past is a serious problem in this type of study. However, all the subjects faced this problem to the same extent.

The healthy worker effect may, however, have played a role in the selection of the sample population at the first phase of the survey. ${ }^{21}$ In particular, it is questionable whether subjects in ill health would be still at work at that date. A longitudinal study is one response to this general problem, on condition that the percentage of subjects lost to follow up is not too high. This condition was met in our study, with $13 \%$ lost to follow up and $9 \%$ seen twice but no longer at work in 1995. This percentage is not constant with age. It is highest in the 1938 generation, that is, for the oldest subjects.

The size of the sample population, the design of the survey, and the small proportion of subjects lost to follow up minimise the possibility of artifacts. Finally, by separating the assessment of factors (in 1990) and the assessment of the effects (CNSP in 1995), the "subject" bias has been lessened. It seems highly unlikely that subjects responded to items about neck and shoulder pains in relation to their answers five years earlier to questions about work related variables. In a recent study, no support was found for differential bias in exposure ratings in studies on musculoskeletal disorders in which subjects reported both exposure and outcome variables. ${ }^{22}$

In this study, we used the term "neck and shoulder pain" to represent a wide range of diagnoses associated with disorders of joints, muscles, tendons, or nerves. Neck and shoulders constitute a physiological complex and it is not always easy to distinguish neck pain from shoulder pain. That is why we have combined the two locations. Our analysis, as in the other studies, is based on perceived problems. ${ }^{23}$ The subjectivity of the measures raises the question of the nature of the observed relation. Are distressing features of work causes of musculoskeletal pain disorder? Or do subjects in pain perceive their work as less satisfactory than their fellow workers, just because of the pain? The prospective design of our study allowed us to investigate the chronological order of the predictors and their assumed health effects.

To increase the reliability of self reporting, a subject was considered as having neck and shoulder pain if he (or she) had experienced pain during at least six months and declared functional limitation. When the subject declared a chronic pain, a detailed clinical examination of the relevant region was performed by the occupational physician. Almost 70\% of subjects were examined by the same occupational physician in 1990 and 1995. In 1990, 68\% of men and 78\% of women had consulted a physician, and $59 \%$ of men and $74 \%$ of women were treated. Since the onset of their neck and shoulder pains, $24 \%$ of men and $27 \%$ of women were at least once on sick leave for a limited period of time.

The incidence rate was not the same according to the geographic area. In 1990, for men, the rate ranged from $5.2 \%$ in La Réunion to $9.9 \%$ in Dauphiné ( $p<0.05$ ), and for women from $11 \%$ in La Réunion to $19.8 \%$ in Dauphiné. In the same way, the frequency of working exposure differed according to the geographic area, and there was a good correlation between the incidence of CNSP and the frequency of exposure. Therefore, we did not include a geographic variable in the logistic models in order to avoid overadjustment.

About $25 \%$ of the subjects with CNSP had declared pains only in that location. The others had associated pains in the back, upper, or lower limbs. This fact could have biased the relations between neck and shoulder pains and working conditions. However, neck and shoulder location was the main pain location for $83 \%$ of cases. By including the variable "musculoskeletal disases in the past" in the model, we took this bias into account to some extent.

Our results showed disappearance of symptoms in some subjects between 1990 and 1995. A typical characteristic of neck pains, in particular, is their episodic and intermittent occurrence. This fact has already been reported in the literature. ${ }^{1824} 25$ Changing job, prevention at the work place, and treatment of the disease could explain these changes. Our results show that, with aging, the disappearance rate is less and less frequent. However, use of the terms "incidence" and "disappearance" is not completely correct. An incidence rate measures the occurrence of new events per unit of persontime. Generally, recurrent events will not be purely incident except for the first one. ${ }^{26}$ For the study of episodic events, such as neck and shoulder pains (a typical characteristic of neck and shoulder pains is their episodic and intermittent occurrence), we had to modify the definition of incidence slightly. In our analysis, an incident symptom was defined as a report of pain (in 1995) which had not been reported in the previous study, in 1990. The discussion is the same for the disappearance rate.

In our study, as in others, women declared more symptoms in the neck and shoulders than men, and less disappearance. The gender difference may be a result of differences in the type of job assigned to women. Women may have a disproportionate amount of the most highly repetitive work and low job 


\section{Main messages}

- The aim was to study the effects of aging and investigate some work related factors as predictors of neck and shoulder chronic pains in a large longitudinal epidemiological survey in France.

- The aging of the workforce appears to contribute to the widespread concern about neck and shoulder chronic pain.

- The study confirms the relations between some adverse working conditions (repetitive work under time constraints, awkward work, high job demand) and the incidence of CNSP, independent of age.

\section{Policy implications}

- To prevent the expected increase in chronic neck and shoulder pain in the aging workforce, preventive measures should be taken at all stages of a working life.

- A better understanding of the regulation of the work activity by the workers can open up new preventive prospects.

control. Moreover, women could cumulate risk factors related to work conditions and activities of daily living.

From a preventive point of view, there is a need for early management of these disorders at the workplace and exploration of the potential to adjust the workplace to fit the needs of the older worker. Our data, however, show that the majority of workers with chronic pain were at work at the end of the study period, coping with their disability. From a research point of view, a better understanding of the regulation of work activity, by the workers themselves, can open up new preventive prospects.

\section{ACKNOWLEDGEMENTS}

This study was supported by grants from the Institut national de la santé et de la recherche médicale (INSERM), Work Ministry, and Research Ministry. We wish to thank all occupational physicians who participated in the ESTEV Survey, and A Bingham for the translation.

\section{Authors' affiliations}

B Cassou, Laboratoire santé-vieillissement, UFR Paris Ouest, RFR 12

INSERM, 49 rue Mirabeau, 75016, Paris, France

F Derriennic, C Monfort, INSERM U 170, Villejuif, France

J Norton, INSERM U 149, Villejuif, France

A Touranchet, Inspection médicale du travail, Nantes, France

\section{REFERENCES}

1 Bernard BP, ed. Musculoskeletal disorders and workplace factors. A critical review of epidemiologic evidence for work-related musculoskeletal disorders of the neck, upper extremity and low back pain. Cincinnati: NIOSH, DHHS (NIOSH), 1997:97-141.
2 Leclerc A, Franchi P, Cristofari MF. Affections périarticulaires des membres supérieurs et organisation du travail. Résultats de l'enquête épidémiologique nationale. Documents pour le médecin du travail 1996;65:13-31

3 Ariëns GAM, van Mechelen W, Bongers PM, et al. Physical risk factors for neck pain. Scand J Work Environ Health 2000;26:7-19.

4 Van der Windt DAWM, Thomas E, Pope DP, et al. Occupational risk factors for shoulder pain: a systematic review. Occup Environ Med 2000;57:433-42

5 Fredriksson K, Alfredsson L, Köster M, et al. Risk factors for neck and upper limb disorders: results from 24 years of follow-up. Occup Environ Med 1999;56:59-66.

6 Eriksen W, Natvig B, Knardahl S, et al. Job characteristics as predictors of neck pain. J Occup Environ Med 1999;41:893-902.

7 Frost P, Andersen JH. Shoulder impingement syndrome in relation to shoulder intensive work. Occup Environ Med 1999;56:494-8.

8 Punnett L, Fine JL, Keyserling WM, et al. Shoulder disorders and postural stress in automobile assembly work. Scand J Work Environ Health 2000;26:283-91.

9 Viikari-Juntura E, Vuori J, Silverstein BA, et al. A life-long prospective study on the role of psycho-social factors in neck-shoulder and low back pain. Spine 1991;16:1056-67.

10 Skov T, Borg V, Orhede E. Psychosocial and physical risk factors for musculoskeletal disorders of the neck, shoulders and lower back in salespeople. Occup Environ Med 1996;53:351-6.

11 Viikari-Juntura E, Riihimäki $H$, Tola $S$, et al. Neck trouble in machine operating, dynamic physical work and sedentary work: a prospective study on occupational and individual risk factors. J Clin Epidemiol 1994;47:1411-22

12 Chiang H-C, KO Y-C, Chen S-S, et al. Prevalence of shoulder and upper-limb disorders among workers in the fish-processing industry. Scand J Work Environ Health 1993;19:126-31.

13 De Zwart BCH, Broersen JPJ, Frings-Dresen MHW, et al. Musculoskeletal complaints in the Netherlands in relation to age, gender and physically demanding work. Int Arch Occup Environ Health 1997;70:352-60.

14 Derriennic F, Touranchet A, Volkoff S. Age, travail, santé: études sur les salariés âgés de 37 à 52 ans (enquête ESTEV 1990). Paris: Les Editions INSERM, 1996.

15 Marquié JC, Paumès D, Volkoff S. Le travail au fil du temps. Toulouse: Octares, 1995.

16 De Zwart BCH, Frings-Dresen MHW, Van Dijk FJH. Physical workload and the ageing worker: a review of the literature. Int Arch Occup Environ Health $1995 ; 68: 1-12$

17 Leino-Arjas P. Smoking and musculoskeletal disorders in the metal industry: a prospective study. Occup Environ Med 1998;55:828-33.

18 Kaergaard A, Andersen JH. Musculoskeletal disorders of the neck and shoulders in female sewing machine operators: prevalence, incidence and prognosis. Occup Environ Med 2000;57:528-34.

19 Magni G, Moreschi C, Rigatti-Luchini S, et al. Prospective study on the relationship between depressive symptoms and chronic musculoskeletal pain. Pain 1994:56:289-97.

20 Miranda H, Vikari-Juntera E, Martikainen R, et al. A prospective study of work related factors and physical exercise as predictors of shoulder pain. Occup Environ Med 2001;58:528-34

21 De Zwart BCH, Broersen JPJ, Van Der Beek AJ, et al. Selection related to musculoskeletal complaints among employees. Occup Environ Med 1997;54:800-6.

22 Toomingas A, Alfredsson L, Kilbom A. Possible bias from rating behavior when subjects rate both exposure and outcome. Scand J Work Environ Health 1997;23:370-7.

23 Schierhout GH, Myers JE. Is self-reported pain an appropriate outcome measure in ergonomic-epidemiologic studies of work-related musculoskeletal disorders? Am J Ind Med 1996;30:93-8.

24 Takala EP, Viikari-Juntura E, Moneta G, et al. Seasonal variation in neck and shoulder symptoms. Scand J Work Environ Health 1992:18:257-61.

25 De Zwart BCH, Broersen JPJ, Frings-Dresen MHW, et al. Repeated survey on change in musculoskeletal complaints relative to age and work demands. Occup Environ Med 1997;54:793-9.

26 Eisen E. Methodology for analysing episodic events. Scand J Work Environ Health 1999;25(suppl 4):36-42. 